\title{
Correlates of antenatal care utilization among women of reproductive age in sub- Saharan Africa: evidence from multinomial analysis of demographic and health surveys (2010-2018) from 31 countries
}

\author{
Sulaimon T. Adedokun ${ }^{1}$ and Sanni Yaya ${ }^{2,3^{*}}$ (i)
}

\begin{abstract}
Background: Despite a global reduction of about 38\% in maternal mortality rate between 2000 and 2017, subSaharan Africa is still experiencing high mortality among women. Access to high quality care before, during and after childbirth has been described as one of the effective means of reducing such mortality. In the sub-region, only $52 \%$ of women receive at least four antenatal visits. This study examined the factors influencing antenatal care utilization in sub-Saharan Africa.

Methods: Data from Demographic and Health Surveys (DHS) of 31 countries involving 235,207 women age 15-49 years who had given birth to children within 5 years of the surveys were used in the study. Multinomial logistic regression model was applied in the analysis.

Results: About 13\% of women in sub-Saharan Africa did not utilize antenatal care while 35 and 53\% respectively partially and adequately utilized the service. Adequate utilization of antenatal care was highest among women age 25-34 years (53.9\%), with secondary or higher education (71.3\%) and from the richest households (54.4\%). The odds of adequate antenatal care utilization increased for women who are educated up to secondary or higher education level, from richest households, working, living in urban areas, exposed to media and did not experience problem getting to health facility or obtaining permission to visit health facility.

Conclusions: This study has revealed information not only on women who did not utilize antenatal care but also on women who partially and adequately utilized the service. The study concluded that the correlates of antenatal care utilization in sub-Saharan Africa include socioeconomic and demographic factors, getting permission to visit health facility, unwillingness to visit health facility alone and problem encountered in reaching the health facility.
\end{abstract}

Keywords: Antenatal care, Sub-Saharan, Africa, Utilization, Women, Multinomial, Maternal, Service, Facility

\footnotetext{
* Correspondence: sanni.yaya@uOttawa.ca

${ }^{2}$ School of International Development and Global Studies, Faculty of Social

Sciences, University of Ottawa, 120 University Private, Ottawa, ON K1N 6N5,

Canada

${ }^{3}$ The George Institute for Global Health, Imperial College London, London,

UK

Full list of author information is available at the end of the article
}

(c) The Author(s). 2020 Open Access This article is licensed under a Creative Commons Attribution 4.0 International License, which permits use, sharing, adaptation, distribution and reproduction in any medium or format, as long as you give appropriate credit to the original author(s) and the source, provide a link to the Creative Commons licence, and indicate if changes were made. The images or other third party material in this article are included in the article's Creative Commons licence, unless indicated otherwise in a credit line to the material. If material is not included in the article's Creative Commons licence and your intended use is not permitted by statutory regulation or exceeds the permitted use, you will need to obtain permission directly from the copyright holder. To view a copy of this licence, visit http://creativecommons.org/licenses/by/4.0/ The Creative Commons Public Domain Dedication waiver (http://creativecommons.org/publicdomain/zero/1.0/) applies to the data made available in this article, unless otherwise stated in a credit line to the data. 


\section{Background}

Although maternal mortality reduced globally by close to $38 \%$ between 2000 and 2017, sub-Saharan Africa is still experiencing high maternal deaths [1]. The subregion accounted for about two-thirds of maternal deaths worldwide in 2017 [1]. Records indicate that among the 15 countries that were considered as hot spots of maternal mortality, 8 were from sub-Saharan Africa. These countries include Somalia, Central Africa Republic, Democratic Republic of Congo, Chad, Guinea, Zimbabwe, Nigeria and Ethiopia [1]. Maternal mortality has been linked to some major predictors such as haemorrhage, sepsis, eclampsia/preeclampsia, ruptured uterus, prolonged obstructed labour and complications of abortion, among others [2].

Access to high quality care before, during and after childbirth has been identified as one of the effective means of reducing maternal mortality [3]. Emphasis has been placed on the importance of antenatal care to maternal and child survival. Antenatal care helps women to prepare for delivery and understand warning signs during pregnancy and childbirth [4]. In addition, antenatal care can (i) be a source of micronutrient supplementation, treatment of hypertension for eclampsia prevention and immunization to prevent tetanus (ii) provide the opportunity for HIV testing and to receive medications to prevent mother-to-child transmission of HIV in the event of pregnant women being HIV positive (iii) provide the opportunity to receive medications and insecticide-treated mosquito nets in order to prevent malaria [4]. In a bid to ensure adequate care for women during pregnancy, WHO at a time recommended at least four antenatal visits for every pregnant woman which has been reviewed upward to eight visits throughout the period of pregnancy. In 2016, the organization developed and published 39 recommendations which are related to five interventions aimed at ensuring a positive pregnancy experience for women [5]. Such interventions include nutritional interventions, maternal and foetal assessment, preventive measures, interventions for common physiological symptoms and health system interventions to improve utilization and quality of antenatal care [5].

However, antenatal care utilization among women in sub-Saharan Africa has been below the global rate. Evidence shows that globally $86 \%$ of pregnant women access antenatal care with a skilled professional at least once while $65 \%$ receive at least 4 visits. Only $52 \%$ of pregnant women in sub-Saharan Africa receive at least 4 visits [4]. Low utilization of antenatal care has been linked to factors such as unplanned pregnancy, previous pregnancy complications, poor autonomy, lack of husband's support, increased distance to health facility, not having health insurance and high costs of services [6]. Other factors that influence antenatal care utilization include maternal age, maternal education, place of residence, household wealth, region, exposure to mass media, number of living children, knowledge during danger signs, previous obstetrical history and quality of care, among others [7-12].

Most of these studies did not use a multi-country approach to study antenatal care utilization. Even studies that used multi-country approach either treated the countries individually or dichotomized the outcome variable into utilized and did not utilize. This study aimed at filling these gaps by applying a multinomial logistic regression model to a pooled data set of countries in subSaharan Africa in order to examine the factors that influence partial utilization, adequate utilization and nonutilization of antenatal care among women in the subregion.

\section{Methods}

\section{Data and sample}

This study used data from Demographic and Health Surveys (DHS) of 31 sub-Saharan African countries which were conducted between 2010 and 2018. The surveys are cross-sectional and obtained information on health and other related issues from women of reproductive age (15-49 years). Sample selection in the surveys involved a two-stage stratified sampling method. Each country was divided into clusters. In the first stage, enumeration areas (EAs) were selected in each cluster and a household listing exercise was conducted in in all selected enumeration areas. The list of households was used as a basis for household selection. In the second stage, households were selected from each enumeration area. In each selected household, women within 15-49 years of age who were either permanent residents or visitors in the night preceding the survey were selected and interviewed. Such women were engaged in a face-to-face interview by field workers who recorded the information in questionnaires. Issues covered in each questionnaire included socioeconomic characteristics, reproductive history, antenatal, delivery and postnatal care, breastfeeding, domestic violence, childhood vaccinations and illnesses, among others. In this study, 235,207 women who have had at least one birth within five years preceding the surveys were involved. The number of women involved in the study and the years of surveys for each country are presented in Table 1.

\section{Outcome variable}

Outcome variable in this study is antenatal care utilization which was measured as not utilized, partially utilized and adequately utilized. The 'not utilized' category involved women who did not attend antenatal clinic at all when they were pregnant. While the 'partially utilized' category included women who attended 
Table 1 Year of survey, number of women and antenatal care utilization in Sub-Saharan Africa using Demographic and Health Surveys 2010-2018

\begin{tabular}{|c|c|c|c|c|c|}
\hline \multirow[t]{2}{*}{ Country } & \multirow{2}{*}{$\begin{array}{l}\text { Year of } \\
\text { survey }\end{array}$} & \multirow{2}{*}{$\begin{array}{l}\text { Number } \\
\text { of } \\
\text { women }\end{array}$} & \multicolumn{3}{|c|}{ Antenatal care utilization } \\
\hline & & & Not utilized (\%) & Partially utilized (\%) & Adequately utilized (\%) \\
\hline Angola & 2015-2016 & 8947 & 22.5 & 20.6 & 56.9 \\
\hline Benin & 2017-2018 & 8994 & 14.0 & 34.7 & 51.3 \\
\hline Burkina Faso & 2010 & 10,364 & 4.6 & 60.8 & 34.6 \\
\hline Burundi & 2016-2017 & 8660 & 0.7 & 49.8 & 49.5 \\
\hline Cameroon & 2011 & 7642 & 13.2 & 24.2 & 62.6 \\
\hline Chad & 2014-2015 & 11,081 & 41.8 & 30.1 & 28.1 \\
\hline Comoros & 2012 & 2015 & 21.2 & 28.3 & 50.5 \\
\hline Congo & 2011-2012 & 6463 & 10.2 & 16.4 & 73.4 \\
\hline Cote d'Ivoire & $2011-2012$ & 5425 & 9.6 & 47.2 & 43.1 \\
\hline Democratic Republic of Congo & 2013-2014 & 11,228 & 13.4 & 41.6 & 45.0 \\
\hline Ethiopia & 2016 & 7193 & 34.8 & 29.0 & 36.2 \\
\hline Gabon & 2012 & 4143 & 9.0 & 22.6 & 68.4 \\
\hline Gambia & 2013 & 5385 & 0.8 & 21.1 & 78.1 \\
\hline Ghana & 2014 & 4294 & 3.6 & 10.4 & 86.0 \\
\hline Guinea & 2018 & 5530 & 17.1 & 48.2 & 34.7 \\
\hline Kenya & 2014 & 14,945 & 6.5 & 39.4 & 54.1 \\
\hline Lesotho & 2014 & 2596 & 5.4 & 20.4 & 74.2 \\
\hline Liberia & 2013 & 5348 & 7.6 & 19.4 & 73.0 \\
\hline Malawi & 2015-2016 & 13,448 & 2.1 & 47.1 & 50.8 \\
\hline Mali & 2018 & 6368 & 24.4 & 33.3 & 42.3 \\
\hline Namibia & 2013 & 3952 & 24.7 & 11.9 & 63.4 \\
\hline Niger & 2012 & 7680 & 15.7 & 51.2 & 33.1 \\
\hline Nigeria & 2018 & 21,792 & 26.1 & 17.4 & 56.5 \\
\hline Rwanda & 2014-2015 & 5955 & 0.8 & 55.1 & 44.1 \\
\hline Senegal & 2010-2011 & 8147 & 7.2 & 47.2 & 45.6 \\
\hline South Africa & 2016 & 3036 & 8.1 & 13.8 & 78.1 \\
\hline Tanzania & 2015-2016 & 7050 & 2.2 & 48.3 & 49.5 \\
\hline Togo & 2013-2014 & 5016 & 7.5 & 37.2 & 55.3 \\
\hline Uganda & 2016 & 10,263 & 2.3 & 37.9 & 59.8 \\
\hline Zambia & 2018 & 7372 & 2.1 & 33.6 & 64.3 \\
\hline Zimbabwe & 2015 & 4833 & 5.7 & 18.1 & 76.2 \\
\hline
\end{tabular}

antenatal clinic less than 4 times, the 'adequately utilized' category involved women who attended antenatal clinic 4 or more times during their pregnancy period.

\section{Independent variables}

In this study, the following independent variables were considered: age, education, household wealth, residence, employment, media exposure, parity, getting permission to use health facility, distance to health facility and unwillingness to visit health facility alone. Age was categorized as 15-24 years, 25-34 years and 35 years and above. Education was defined as none, primary and secondary or higher. Household wealth was measured through the ownership of household items such as radio, television, car, bicycle, agricultural land, farm animals and housing characteristics such as toilet facilities, water source, flooring/roofing materials, etc. Households were awarded scores based on the number of items available in the households. The scoring was done using principal component analysis. The result was thereafter expressed in five quintiles namely, poorest, poorer, middle, richer and richest. Residence was grouped into urban and rural. Employment was defined as working for those who engaged in one economic activity or another and not 
working for those who did not engage in economic activities. Media exposure was categorized as exposed and not exposed. Parity was categorized from 1 to 5 or more. Getting permission to use health facility, distance to health facility and unwillingness to visit health facility alone were measured as problem for women who experienced difficulty in respect of each of the variables and not a problem for those who did not experience any difficulty.

\section{Statistical analysis}

Analysis in this study was carried out in three stages. The first stage involved pooling data sets of the 31 countries together in order to have a single data set for subSaharan Africa. To ensure that under-enumeration and over-enumeration in the surveys were adequately adjusted for, a weighting factor $\left(\frac{\boldsymbol{v 0 0 5}}{\mathbf{1 0 0 0 0 0 0}}\right)$ was applied to the data. The data were further defined as survey data using the svyset command. In the second stage, Chi-Square test was used to describe the relationships between antenatal care utilization and the independent variables. The third stage involved multivariate analysis where multinomial logistic regression was applied. This is a statistical technique used when the outcome variable has more than two categories. The multinomial logistic regression model is given as:

$$
\begin{aligned}
& \operatorname{In}\left(\frac{\pi\left(Y=j \mid x_{1}, x_{2}, \ldots, x_{p}\right)}{\pi\left(Y=J \mid x_{1}, x_{2}, \ldots, x_{p_{1}}\right)}\right) \\
& \quad=\alpha_{j}+\beta_{j 1} X_{1}+\beta_{j 2} X_{2}+\ldots+\beta_{j p} X_{p}
\end{aligned}
$$

Where $j=1,2, \ldots, J-1$ (categories of the outcome variable) and $J$ is the base outcome; $\alpha_{j}$ represent the intercepts and $\beta_{j 1}, \ldots \beta_{j p}$ represent the logit coefficients; and $X_{1} \ldots X_{p}$ represent the independent variable [13].

Base outcome in the analysis is none (women who did not attend antenatal clinic). Odds ratios including their corresponding 95\% confidence intervals were thereafter obtained. Three $\alpha$ levels $(0.05,0.01$ and 0.001$)$ were specified for the interpretation of statistical significance. Stata 14 statistical package was used to perform all the statistical operations.

\section{Results}

\section{Descriptive statistics}

Table 1 shows that the countries with the highest percentage of women who did not utilize antenatal care during their pregnancy period include Chad (41.8\%), Ethiopia (34.8\%) and Nigeria (26.1\%). Countries with the highest proportions of women who partially utilized antenatal care are Burkina Faso (60.8\%), Rwanda (55.1\%) and Niger (51.2\%). With respect to adequate utilization of antenatal care, countries with the highest proportions include Ghana (86\%), Gambia (78.1\%) and South Africa (78.1\%). Results in Table 2 show that about 13\% of women in sub-Saharan Africa did not utilize antenatal care, $35 \%$ partially utilized antenatal care and 53\% adequately utilized antenatal care. Adequate utilization of antenatal care was highest among women age 25-34 years (53.9\%), with secondary or higher education (71.3\%), from the richest households (68.4\%) and living in urban area (65.4\%). More than half of working women (54.4\%) and those who are exposed to media (59.4\%) adequately utilized antenatal care. Majority of women with parity 1 adequately utilized antenatal care. Adequate utilization of antenatal care was predominant among women who declared that they had no problem with respect to getting permission to use health facility (55.3\%), reaching the health facility (57.9\%) not willing to visit health facility alone (55.5\%).

\section{Correlates of antenatal care utilization}

Results from multinomial logistic regression showing the correlates of antenatal care utilization are presented in Table 3.

\section{Partial antenatal care utilization}

There is a significant relationship between age and partial utilization of antenatal care as women age 25-34 years and 35 years and above are 6 and 16\% respectively less likely to utilize antenatal care partially compared to women age 15-24years. Women with secondary or higher education are $34 \%$ more likely to partially utilize antenatal care compared to uneducated women. Household wealth indicates that women from richest households are $133 \%$ more likely to partially utilize antenatal care than women from poorest households. However, results from residence show that women living in urban areas are $16 \%$ less likely to partially utilize antenatal care compared to rural women. The odds of partial utilization of antenatal care increased by factors of 1.49 and 1.78 respectively for working women and those who have media exposure. Women with parity 1 are 16 times more likely to partially utilize antenatal care compared to women with parity 5 or more. The odds of utilizing antenatal care partially increased by factors of 1.59 and 1.09 respectively for women who did not experience any problem with respect to getting permission to use health facility and reaching the health facility. Women who did not experience any problem in respect of not willing to visit health facility alone are $26 \%$ more likely to partially utilize antenatal care compared to women who experienced problems.

\section{Adequate antenatal care utilization}

Results indicate that women who are within the age groups 25-34 years and 35 years and above are 23 and 
Table 2 Relationship between correlates and antenatal care utilization in sub-Saharan Africa using Demographic and Health Surveys 2010-2018

\begin{tabular}{|c|c|c|c|c|c|}
\hline \multirow[t]{4}{*}{ Variable } & \multicolumn{5}{|c|}{ Antenatal care utilization } \\
\hline & Not utilized & Partially utilized & Adequately utilized & Total & $p$-value \\
\hline & N (\%) & N (\%) & N (\%) & $\mathrm{N}(\%)$ & \\
\hline & $29,892(12.7)$ & $81,058(34.5)$ & $124,256(52.8)$ & $235,207(100.0)$ & \\
\hline \multicolumn{6}{|l|}{$\overline{\text { Age }}$} \\
\hline $15-24$ & $8389(11.8)$ & $25,492(35.9)$ & $37,103(52.3)$ & $70,984(100.0)$ & \\
\hline $25-34$ & $13,186(12.3)$ & $36,174(33.8)$ & $57,769(53.9)$ & $107,129(100.0)$ & \\
\hline $35+$ & $8317(14.6)$ & 19,393 (34.0) & $29,384(51.4)$ & $57,094(100.0)$ & $<0.001$ \\
\hline \multicolumn{6}{|l|}{ Education } \\
\hline None & $20,445(22.4)$ & $35,831(39.2)$ & $35,008(38.4)$ & $91,284(100.0)$ & \\
\hline Primary & $5912(7.5)$ & $30,126(38.2)$ & $42,915(54.3)$ & $78,953(100.0)$ & \\
\hline Secondary/higher & $3535(5.4)$ & $15,102(23.2)$ & $46,333(71.3)$ & $64,970(100.0)$ & $<0.001$ \\
\hline \multicolumn{6}{|c|}{ Household wealth index } \\
\hline Poorest & $11,989(20.8)$ & $21,551(37.3)$ & $24,212(41.9)$ & $57,752(100.0)$ & \\
\hline Poorer & $7291(14.4)$ & $18,856(37.1)$ & $24,662(48.5)$ & $50,809(100.0)$ & \\
\hline Middle & $5034(10.9)$ & $16,656(36.0)$ & $24,568(53.1)$ & $46,258(100.0)$ & \\
\hline Richer & $3725(8.8)$ & $13,827(32.7)$ & $24,763(58.5)$ & $42,313(100.0)$ & \\
\hline Richest & $1853(4.9)$ & $10,169(26.7)$ & $26,051(68.4)$ & $38,073(100.0)$ & $<0.001$ \\
\hline \multicolumn{6}{|l|}{ Residence } \\
\hline Urban & $5302(7.1)$ & $20,376(27.5)$ & $48,565(65.4)$ & $74,243(100.0)$ & \\
\hline Rural & $24,590(15.3)$ & $60,683(37.7)$ & $75,691(47.0)$ & $160,964(100.0)$ & $<0.001$ \\
\hline \multicolumn{6}{|l|}{ Employment } \\
\hline Not working & $14,176(16.6)$ & $28,314(33.2)$ & $42,803(50.2)$ & $85,293(100.0)$ & \\
\hline Working & 15,089 (10.6) & $49,599(35.0)$ & $77,204(54.4)$ & $141,892(100.0)$ & $<0.001$ \\
\hline \multicolumn{6}{|l|}{ Media exposure } \\
\hline Not exposed & $18,118(22.1)$ & $30,527(37.2)$ & $33,368(40.7)$ & $82,013(100.0)$ & \\
\hline Exposed & $11,652(7.6)$ & $50,399(33.0)$ & $90,703(59.4)$ & $152,754(100.0)$ & $<0.001$ \\
\hline \multicolumn{6}{|l|}{ Parity } \\
\hline 1 & $4314(8.9)$ & $15,290(31.7)$ & $28,669(59.4)$ & $48,273(100.0)$ & \\
\hline 2 & 4631 (10.6) & 14,396 (32.9) & $24,724(56.5)$ & $43,751(100.0)$ & \\
\hline 3 & 4291 (11.6) & 12,496 (33.8) & $20,143(54.5)$ & $36,930(100.0)$ & \\
\hline 4 & 3993 (13.2) & $10,446(34.6)$ & $15,751(52.2)$ & $30,190(100.0)$ & \\
\hline $5+$ & $12,663(16.7)$ & $28,431(37.4)$ & 34,969 (45.9) & $76,063(100.0)$ & $<0.001$ \\
\hline \multicolumn{6}{|c|}{ Getting permission to use health service } \\
\hline A problem & $8265(20.6)$ & $14,021(34.9)$ & $17,866(44.5)$ & $40,152(100.0)$ & \\
\hline Not a problem & $17,402(10.0)$ & $60,604(34.7)$ & $96,462(55.3)$ & $174,468(100.0)$ & $<0.001$ \\
\hline \multicolumn{6}{|c|}{ Distance to health facility } \\
\hline A problem & $14,437(16.4)$ & $32,420(36.9)$ & $40,961(46.7)$ & $87,818(100.0)$ & \\
\hline Not a problem & $11,235(8.9)$ & $42,204(33.2)$ & $73,368(57.9)$ & $126,807(100.0)$ & $<0.001$ \\
\hline \multicolumn{6}{|c|}{ Not willing to go to health facility alone } \\
\hline A problem & $8970(18.7)$ & $17,144(35.7)$ & $21,964(45.6)$ & $48,078(100.0) 3$ & \\
\hline Not a problem & $16,698(10.0)$ & $57,478(34.5)$ & $92,358(55.5)$ & $166,534(100.0)$ & $<0.001$ \\
\hline
\end{tabular}


Table 3 Results of multinomial logistic regression for antenatal care utilization in sub-Saharan Africa using Demographic and Health Surveys 2010-2018

\begin{tabular}{|c|c|c|}
\hline \multirow[t]{2}{*}{ Variable } & \multicolumn{2}{|l|}{ Antenatal care utilization } \\
\hline & Partially utilized vs Not utilized & Adequately utilized vs Not utilized \\
\hline Age & $\mathrm{aOR}(95 \% \mathrm{Cl})$ & $\mathrm{aOR}(95 \% \mathrm{Cl})$ \\
\hline $15-24$ & 1 & 1 \\
\hline $25-34$ & $0.94^{*}(0.90-0.0 .99)$ & $1.23^{* * *}(1.18-1.29)$ \\
\hline $35+$ & $0.84^{* * *}(0.79-0.89)$ & $1.29^{* * *}(1.22-1.36)$ \\
\hline \multicolumn{3}{|l|}{ Education } \\
\hline None & 1 & 1 \\
\hline Primary & $2.24^{* * *}(2.16-2.32)$ & $3.14^{* * *}(3.03-3.25)$ \\
\hline Secondary/higher & $1.34^{* * *}(1.28-1.41)$ & $3.36^{* * *}(3.22-3.52)$ \\
\hline \multicolumn{3}{|c|}{ Household wealth index } \\
\hline Poorest & 1 & 1 \\
\hline Poorer & $1.29^{* * *}(1.24-1.34)$ & $1.34^{* * *}(1.29-1.39)$ \\
\hline Middle & $1.61^{* * *}(1.54-1.68)$ & $1.64^{* * *}(1.57-1.71)$ \\
\hline Richer & $1.88^{* * *}(1.78-1.98)$ & $1.89 * * *(1.79-1.99)$ \\
\hline Richest & $2.33^{* * *}(2.17-2.49)$ & $2.41^{* * *}(2.25-2.58)$ \\
\hline \multicolumn{3}{|l|}{ Residence } \\
\hline Urban & $0.84^{* * *}(0.80-0.88)$ & $1.16^{* * *}(1.11-1.20)$ \\
\hline Rural & 1 & 1 \\
\hline \multicolumn{3}{|l|}{ Employment } \\
\hline Not working & 1 & 1 \\
\hline Working & $1.49^{* * *}(1.44-1.53)$ & $1.54^{* * *}(1.49-1.58)$ \\
\hline \multicolumn{3}{|l|}{ Media exposure } \\
\hline Not exposed & 1 & 1 \\
\hline Exposed & $1.78^{* * *}(1.72-1.83)$ & $2.11^{* * *}(2.05-2.18)$ \\
\hline \multicolumn{3}{|l|}{ Parity } \\
\hline 1 & $1.16^{* * *}(1.09-1.24)$ & $1.65^{* * *}(1.55-1.75)$ \\
\hline 2 & $1.04(0.99-1.10)$ & $1.33^{* * *}(1.26-1.40)$ \\
\hline 3 & $1.03(0.98-1.08)$ & $1.23^{* * *}(1.17-1.29)$ \\
\hline 4 & $1.00(0.95-1.05)$ & $1.15^{* * *}(1.09-1.21)$ \\
\hline $5+$ & 1 & 1 \\
\hline \multicolumn{3}{|c|}{ Getting permission to use health service } \\
\hline A problem & 1 & 1 \\
\hline Not a problem & $1.59^{* * *}(1.53-1.65)$ & $1.73^{* * *}(1.67-1.79)$ \\
\hline \multicolumn{3}{|c|}{ Distance to health facility } \\
\hline A problem & 1 & 1 \\
\hline Not a problem & $1.09^{* * *}(1.05-1.13)$ & $1.19 * * *(1.16-1.24)$ \\
\hline \multicolumn{3}{|c|}{ Not willing to go to health facility alone } \\
\hline A problem & 1 & 1 \\
\hline Not a problem & $1.26^{* * *}(1.21-1.31)$ & $1.27^{* * *}(1.22-1.31)$ \\
\hline
\end{tabular}

Level of significance at ${ }^{*} p<0.05,{ }^{* *} p<0.01,{ }^{* *} p<0.001$

$29 \%$ respectively more likely to adequately utilize antenatal care compared to women of age group 15-24. While the odds of adequate utilization of antenatal care increased by a factor of 3.36 for women with secondary or higher education, the odds increased by a factor of 2.41 for women from richest households. Women who 
are living in urban areas and those who are working are 16 and 54\% respectively more likely to utilize antenatal care adequately. The odds of utilizing antenatal care adequately increased by a factor of 2.11 for women who are exposed to media. Women with parity 1 are $65 \%$ more likely to adequately utilize antenatal care compared to women with parity 5 or more. The odds of utilizing antenatal care adequately increased by factors of 1.73 and 1.19 respectively for women who did not experience problems getting permission to use health facility and reaching the health facility. Women who did not experience problems with respect to unwillingness to visit health facility alone are $27 \%$ more likely to adequately utilize antenatal care compared to women who experienced problems.

\section{Discussion}

This study has shown that $35 \%$ of women in subSaharan Africa partially utilized antenatal care while 53\% adequately utilized the service. However, $13 \%$ of the women did not utilize the service at all. The study also revealed the factors influencing antenatal care utilization. A significant relationship exists between women's age and adequate utilization of antenatal care [14-16]. The higher the age of a woman, the more the woman would adequately utilize antenatal care. This indicates that young women (15-24 years) probably lack experience in pregnancy care compared to older women. Results also show that women with secondary or higher education are more likely to utilize antenatal care adequately than uneducated women. This implies that the higher the level of education, the more a woman utilizes antenatal care [17-19]. Education promotes a better enlightenment on issues especially health-related ones and this gives women with secondary or higher education an advantage over their uneducated counterparts. Household wealth shows a significant relationship with antenatal care utilization as women from richest households have higher probability of utilizing antenatal care adequately than women from poorest households [20-24]. Poverty at household level may constitute a great barrier to accessing maternal health services. Women from poor households may not have the financial resources needed to either get registered at clinics or pay for the services rendered during the prenatal period. This may lead to a situation where such women would partially attend the clinics or not attend at all. Residence is another factor which influences antenatal care utilization [25-28]. Rate of adequate utilization of antenatal care in urban areas is higher than that of rural areas. It is obvious that infrastructural facilities are well spread in urban areas and this goes for health facilities which are inadequately provided in rural areas. This gives women in urban areas the opportunity to utilize health services. At the same time, women in urban areas have access to information on health-related issues more than women in rural areas. Results further show that the odds of adequate antenatal care utilization is higher among working women than non-working women $[29,30]$. This may be linked to the fact that working women, particularly those in the formal sector, have the opportunity of enjoying health insurance scheme which caters for pregnancy care. In some countries, provisions are made to accommodate women working in the informal sector in the scheme. This enhances antenatal care utilization among such category of women compared to non-working women. Media exposure plays an important role in antenatal care utilization as women who are exposed to media have higher percentage of adequate antenatal care utilization than non-exposed women [31-33]. Access to information on health issues is a significant component of maternal health. When women are furnished with adequate information on maternal health services, it tends to increase their utilization of such services. This informed the implementation of programmes promoting maternal health on radio and television. Parity is another factor which is significantly related to adequate utilization of antenatal care [34-36]. Women with 1 parity are more likely to utilize antenatal care adequately than women with 5 or more parity. This means that the more the parity the less the adequate utilization of antenatal care by women. This finding is corroborated by previous studies which emphasized that poor antenatal care utilization among high parity women might be linked to increased confidence from previous pregnancies and childbirth [6, 8, 37-39]. With respect to getting permission from spouse in order to use health service, women who claimed that they did not experience any problem getting permission are more likely to utilize antenatal care adequately than women who experienced problems in that regard [40, 41]. This is an aspect where decision to utilize health service by women is hinged on the consent of their husbands. If such husbands do not see any need for their wives to attend antenatal care, it becomes a problem for such women to access health service as acting against the decision of their husbands may be viewed as an unpardonable act of insubordination. This may eventually lead to a serious marital conflict. More so, rate of adequate utilization of antenatal care is higher among women who claimed that they did not experience any problem in respect of distance covered to access health facility compared to women who complained that they experienced difficulty. Problems in terms of distance could imply that the location of health facility is far from the women's residence and the means of getting there is problematic [39, 42-44]. For instance, women living in areas where there is poor road network such that vehicles hardly ply the road or areas where 
transport system is irregular would find it difficult access health facility. This shows that even when such women are willing to utilize antenatal care, their inability to navigate easily to the facility will prevent them from making use of such service. Unwillingness to visit health facility alone is another factor determining adequate antenatal care utilization. In some cases, women may not be willing to visit health facility without being accompanied by either their husbands or close relatives based on their beliefs or conviction [45]. Women who are of the opinion that unwillingness to visit health facility alone is not their problem are more likely to utilize antenatal care adequately than women who claimed that it is their problem. This implies that the more the number of women who consider not visiting health facility alone, the less the proportions of women that would adequately utilize antenatal care.

\section{Policy implications}

With $13 \%$ of women not utilizing antenatal care, 35\% partially utilizing it and 53\% adequately utilizing it, antenatal care utilization in sub-Saharan Africa remains a big health challenge. This may impede the efforts at reducing maternal mortality in the region. It is apparent that more efforts need to be made in order to increase the proportions of women that would adequately utilize antenatal care. One of the ways of achieving this is through provision of more health facilities particularly in areas where they are grossly inadequate. Rural areas should be considered in this regard. There is a need to increase awareness on importance of antenatal care utilization among young woman who are just beginning their childbearing experience. Such awareness initiatives should be organized in both rural and urban areas and emphasis should be placed on the risks involved in not attending antenatal care at all or partially attending it. It is necessary to propagate such awareness on radio and television programmes. Efforts should also be made towards increasing proportions of educated women in each country. Incentives that would encourage enrolment of female children in school should be introduced. Poverty alleviation initiatives both at individual and household levels through social security, employment opportunities and funds for business activities should be pursued. It is also necessary for governments at different levels to introduce initiatives that would actively involve men in maternal health care. This is important in order to address the problems associated with husbands not granting their wives permission to visit health facility or not willing to accompany them to utilize health service. Involving them in maternal health care would improve their awareness on adequate antenatal care utilization which would make them support their wives during and after pregnancy. This initiative should be undertaken at local and national levels and should be part of maternal health care agenda which would be supervised by Ministry of Health in each country.

\section{Strengths and weaknesses}

This study is based on data sets obtained from crosssectional surveys which were conducted over some periods of time. This has only provided the opportunity to arrive at associated factors of antenatal care utilization but not the causes. Because the surveys were conducted at different periods, the variations in the characteristics of the respondents which occurred over these periods among the countries could not be harmonized. The analysis could not also include the time and countries as variables. It should also be noted that responses in the surveys were obtained from participants who reported events that had occurred in the past. Such responses may be fraught with recall error. In spite of these weaknesses, the study has examined the correlates of antenatal care utilization by applying multinomial logistic regression model which disaggregated the outcome variable into three categories. This provided an in-depth explanation on the effects of the correlates on each category. This is in contrast to most previous studies that modelled the outcome variable as binary. Moreover, the study used large data sets from 31 countries in subSaharan Africa which made the findings to be robust and generalizable.

\section{Conclusions}

The study has revealed information not only on women who did not utilize antenatal care in sub-Saharan Africa, but also those who partially or adequately utilized it. The study has also shown that apart from socioeconomic and demographic factors, other factors that influence antenatal care utilization include getting permission to visit health facility, unwillingness to visit health facility alone and distance to health facility. There is a need to address the poor utilization of antenatal care by developing a maternal health service utilization model which would consider the different factors.

\footnotetext{
Abbreviations

aOR: Adjusted Odds Ratio; Cl: Confidence Interval; DHS: Demographic and Health Survey; UNICEF: United Nations International Children's Emergency Fund; WHO: World Health Organization
}

\section{Acknowledgements}

The authors thank the MEASURE DHS project for their support and for free access to the original data.

\section{Authors' contributions}

STA and SY conceptualised and designed the study, STA acquired, analysed, interpreted the data, STA and SY drafted and revised the manuscript, SY critically reviewed the manuscript. SY had final responsibility to submit for publication. Both authors approved the final manuscript as submitted and agree to be accountable for all aspects of the work. 


\section{Funding}

The authors received no specific funding for this work.

\section{Availability of data and materials}

Data used in this study were obtained from the DHS Program and available at:

https://dhsprogram.com/data/available-datasets.cfm.

\section{Ethics approval and consent to participate}

Ethics approval was not required for this study since the data is secondary and is available in the public domain. More details regarding DHS data and ethical standards are available at: http://goo.gl/ny8T6X

\section{Consent for publication}

Not Applicable.

\section{Competing interests}

The authors declare that they have no competing interest.

\section{Author details}

${ }^{1}$ Department of Demography and Social Statistics, Obafemi Awolowo University, Ile-Ife, Nigeria. ${ }^{2}$ School of International Development and Global Studies, Faculty of Social Sciences, University of Ottawa, 120 University Private, Ottawa, ON K1N 6N5, Canada. ${ }^{3}$ The George Institute for Global Health, Imperial College London, London, UK.

\section{Received: 4 November 2020 Accepted: 7 December 2020}

Published online: 14 December 2020

\section{References}

1. Maternal Mortality: Key Facts [https://www.who.int/news-room/fact-sheets/ detail/maternal-mortality. Accessed 5 August 2020]

2. Sager R, Kongnyuy E, Adebimpe WO, Omosehin O, Ogunsola EA, Sanni B. Causes and Contributory Factors of Maternal Mortality: Evidence From Maternal and Perinatal Death Surveillance and Response in Ogun State, Southwest Nigeria. BMC Pregnancy Childbirth. 2019;19(63).

3. Trends in Maternal Mortality [https://data.unicef.org/resources/trendsmaternal-mortality-2000-2017/. Accessed 5 August 2020].

4. Antenatal Care [https://data.unicef.org/topic/maternal-health/antenatalcare/. Accessed 5 August 2020].

5. WHO Recommendations on Antenatal Care for a Positive Pregnancy Experience [https://apps.who.int/iris/bitstream/handle/10665/250796/ 9789241549912-eng.pdf.ijsessionid=FC8B1A05DB47E824E012407A5C1EB4 A8? sequence=1. Accessed 5 August 2020].

6. Okedo-Alex IN, Akamike IC, Ezeanosike OB, Uneke CJ. Determinants of antenatal care utilisation in sub-Saharan Africa: a systematic review. BMJ Open. 2019;9:e031890.

7. Tiruaynet K, Muchie KF. Determinants of Utilization of Antenatal Care Services in Benishangul Gumuz Region, Western Ethiopia: A Study Based on Demographic and Health Survey. BMC Pregnancy Childbirth. 2019;19(115).

8. Ali SA, Dero AA, Ali SA, Ali GB. Factors Affecting the Utilization of Antenatal Care among Pregnant Women: A literature Review. J Pregnancy Neonatal Med. 2018;2(2).

9. Basha GW. Factors affecting the utilization of a minimum of four antenatal Care Services in Ethiopia. Obstet Gynecol Int. 2019;2019.

10. Kim KH, Choi JW, Oh J, Moon J, You S, Woo Y. What Are the Barriers to Antenatal Care Utilization in Rufisque District, Senegal?: A Bottleneck Analysis. J Korean Med Sci. 2019;34(7).

11. Tekelab T, Chojenta C, Smith R, Loxton D. Factors Affecting Utilization of Antenatal Care in Ethiopia: A systematic Review and Meta-analysis. PLoS One. 2019;14(4)

12. Terefe AN, Gelaw AB. Determinants of antenatal care visit utilization of child-bearing mothers in Kaffa, Sheka, and bench Maji zones of SNNPR, southwestern Ethiopia. Health Serv Res Managerial Epidemiol. 2019;6.

13. Liu X. Applied ordinal logistic regression using Stata. U. S. A.: SAGE Publications Ltd; 2016

14. Awasthi MS, Awasthi KR, Thapa HS, Saud B, Pradhan S, Khatry RA. Utilization of antenatal Care Services in Dalit Communities in Gorkha, Nepal: A CrossSectional Study. J Pregnancy. 2019;2019.
15. Akowuah JA, Agyei-Baffour P, Awunyo-Vitor D. Determinants of Antenatal Healthcare Utilisation by Pregnant Women in Third Trimester in Peri-Urban Ghana. J Trop Med. 2018;2018.

16. Kakati R, Barua K, Borah M. Factors Associated with the Utilization of Antenatal Care Services in Rural Areas of Assam, India. Int J Commun Med Public Health. 2016;3(10)

17. Wondimu W, Girma M, Agedew E. Antenatal Care Utilization and Associated Factors among Reproductive Age Mother in Ari Woreda, South Omo Zone. Reprod Syst Sex Disord. 2017;6(1)

18. Atuhaire S, Mugisha JF. Determinants of Antenatal Care Visits and their Impact on the Choice of Birthplace among Mothers in Uganda: A Systematic Review. Obstetrics Gynecol Int J. 2020;11(1).

19. Abera A, Asseffa NA, Obssa MS, Balla ET, Koyire MM. Utilization of Focused Antenatal Care Service and Associated Factors among Women in Southern Ethiopia. Int J Adv Med Health Res. 2019;6(2).

20. Fagbamigbe AF, Idemudia ES. Wealth and Antenatal Care Utilization in Nigeria: Policy implications. Health Care Women Int. 2016;38(1).

21. Sanogo NA, Yaya S. Wealth status, health insurance, and maternal health care utilization in Africa: evidence from Gabon. Biomed Res Int. 2020.

22. Adewuyi EO, Auta A, Khanal V, Bamidele OD, Akuomo CP, Adefemi K, Tapshak SJ, Zhao Y. Prevalence and Factors Associated with Underutilization of Antenatal Care Services in Nigeria: A Comparative Study of Rural and Urban Residences Based on the 2013 Nigeria demographic and health survey. PLoS One. 2018;13(5).

23. Shibre G, Mekonnen W. Socio-economic Inequalities in ANC Attendance among Mothers Who Gave Birth in the Past 12 Months in Debre Brehan Town and Surrounding Rural Areas, North East Ethiopia: A Communitybased Survey. Reprod Health. 2019;16(99).

24. Adedokun ST, Uthman OA. Women who have not utilized health Service for Delivery in Nigeria: who are they and where do they live? BMC Pregnancy Childbirth. 2019;19(93):1-14.

25. Ali N, Sultana M, Sheikh N, Akram R, Mahumud RA, Asaduzzam M, Saker AR. Predictors of optimal antenatal care service utilization among adolescents and adult women in Bangladesh. Health Serv Res Managerial Epidemiol. 2018;5.

26. Yeneneh A, Alemu K, Dadi AF, Alamirrew A. Spatial Distribution of Antenatal Care Utilization and Associated Factors in Ethiopia: Evidence From Ethiopian Demographic Health Surveys. BMC Pregnancy Childbirth. 2018;18(242).

27. Abegaz KH, Habtewold RD. Trend and Barriers of Antenatal Care Utilization From 2000 to 2016 Ethiopian DHS: a data mining approach. Scientific Afr. 2019:3.

28. Yaya S, Bishwajit G, Ekholuenetale M, Shah V, Kadio B, Udenigwe O. Timing and Adequate Attendance of Antenatal Care Visits among Women in Ethiopia. PLoS One. 2017;12(9).

29. Gitonga E. Determinants of focused antenatal care uptake among women in Tharaka Nithi County, Kenya. Adv Public Health. 2017;2017.

30. Barasa KS, Wanjoya AK, Waititu AG. Analysis of Determinants of Antenatal Care Services Utilization in Nairobi County Using Logistic Regression Model. Am J Theor Appl Stat. 2015:4(5).

31. PP, Chouhan P. Socio-demographic Factors Influencing Utilization of Maternal Health Care Services in India. Clin Epidemiol Global Health. 2020;8(3).

32. Aliyu AA, Dahiru T. Predictors of Delayed Antenatal Care (ANC) Visits in Nigeria: Secondary Analysis of 2013 Nigeria demographic and health survey (NDHS). Pan Afr Med J. 2017, 26(124).

33. Mezmur M, Navaneetham K, Letamo G, Bariagaber H. Socioeconomic Inequalities in the Uptake of Maternal Healthcare Services in Ethiopia. BMC Health Serv Res. 2017;17(367).

34. Laksono AD, Rukmini R, Wulandari RD. Regional Disparities in Antenatal Care Utilization in Indonesia. PLoS One. 2020;15(2).

35. Dahiru T, Oche OM. Determinants of Antenatal Care, Institutional Delivery and Postnatal Care Services Utilization in Nigeria. Pan Afr Med J. 2015:22(1).

36. Deepak C, Jauhari N, Dhungana H. A Study on Utilization of Maternal Health Services and Factors Influencing the Utilization in Urban Slums of Lucknow. Int J Med Public Health. 2018;8(2).

37. Kumar G, Choudhary TS, Srivastava A, Upadhyay RP, Taneja S, Bahl R, Martines J, Bhan MK, Bhandari N, Mazumder S. Utilization,Equity and Determinants of Full Antenatal Care in India: Analysis from the National Family Health Survey 4. BMC Pregnancy Childbirth. 2019;19(327).

38. Guliani H, Sepehri A, Serieux J. Determinants of prenatal care use: evidence from 32 low-income countries across Asia, sub-Saharan Africa and Latin America. Health Policy Plan. 2014;29:589-602. 
39. Ali SA, Ali SA, Feroz A, Saleem S, Fatmai Z, Kadir MM. Factors Affecting the Utilization of Antenatal Care among Married Women of Reproductive Age in the Rural Thatta, Pakistan: Findings From a Community-based Casecontrol Study. BMC Pregnancy Childbirth. 2020;20(355).

40. Thapa NR. Women's Autonomy and Antenatal Care Utilization in Nepal: A study From Nepal demographic and Health Survey 2016. MOJ Women's Health. 2019, 8(4)

41. Abimbola JM, Makanjuola AT, Ganiyu SA, Babatunde UMM, Adekunle DK, Olatayo AA. Pattern of Utilization of Ante-natal and Delivery Services in a Semi-urban Community of North-Central Nigeria. Afr Health Sci. 2016;16(14).

42. Warri D, George A. Perceptions of Pregnant Women of Reasons for Late Initiation of Antenatal Care: A Qualitative Interview Study. BMC Pregnancy Childbirth. 2020;20(70)

43. Nyathi L, Tugli AK, Tshitangano TG, Mpofu M. Investigating the Accessibility Factors that Influence Antenatal Care Services Utilisation in Mangwe District, Zimbabwe. Afr J Primary Health Care Fam Med. 2017;9(1).

44. Ziblim SD, Yidana A, Mohammed AR. Determinants of Antenatal Care Utilization among Adolescent Mothers in the Yendi Municipality of Northern Region, Ghana. Ghana J Geogr. 2018;10(1).

45. Rurangirwa AA, Mogren I, Nyirazinyoye L, Ntaganira J, Gunilla K. Determinants of Poor Utilization of Antenatal Care Services among Recently Delivered Women in Rwanda: A Population Based Study. BMC Pregnancy Childbirth. 2017;17(142).

\section{Publisher's Note}

Springer Nature remains neutral with regard to jurisdictional claims in published maps and institutional affiliations.

Ready to submit your research? Choose BMC and benefit from:

- fast, convenient online submission

- thorough peer review by experienced researchers in your field

- rapid publication on acceptance

- support for research data, including large and complex data types

- gold Open Access which fosters wider collaboration and increased citations

- maximum visibility for your research: over $100 \mathrm{M}$ website views per year

At $\mathrm{BMC}$, research is always in progress.

Learn more biomedcentral.com/submissions 